\title{
A 12 year follow up study in the general population on prognostic factors of cartilage loss in osteoarthritis of the knee
}

\author{
Jan S A G Schouten, Frank A van den Ouweland, Hans A Valkenburg
}

\begin{abstract}
The natural history and prognostic factors of cartilage loss in osteoarthritis of the knee were studied in subjects from a general population survey on rheumatic diseases in 1975-8. Baseline data were collected by questionnaire, physical examination, and weightbearing anteroposterior knee radiographs. Follow up of the subjects aged 46-68 years with radiological osteoarthritis grade 2-4 (Kellgren) took place in 1988-9. Cartilage loss was assessed by two observers who scored the change in joint space width between two radiographs. Thirty four per cent had cartilage loss. Prognostic factors and adjusted odds ratios (ORs) (95\% confidence intervals) were: body mass index $0 R=11 \cdot 1$ (3.3 to 37.3) fourth $v$ first quartile; body weight $O R=7.9(2.6$ to 24.0$)$ third $v$ first tertile; age $\mathrm{OR}=3.8(1.1$ to 13.4$)>60 v \leqslant 49$ years; Heberden's nodes $O R=6.0$ (1.5 to 23.1); clinical diagnosis of generalised osteoarthritis $\mathrm{OR}=3.3(1.3$ to 8.3$)$; and previous bow legs or knock knees $\mathrm{OR}=5 \cdot 1(1 \cdot 1$ to $23 \cdot 1)$. The relation of age with cartilage loss was also confounded by the presence of Heberden's nodes or a diagnosis of generalised osteoarthritis. There was no statistically significant relation for gender, meniscectomy, injury, uric acid concentration, chondrocalcinosis, smoking, and occupation related factors, except possibly standing.
\end{abstract}

(Ann Rheum Dis 1992; 51: 932-937)

Insight into the natural history and prognostic factors of a disease is needed to influence its course. For such a common disease as osteoarthritis of the knee, however, surprisingly little is known about the natural history and prognostic factors. ${ }^{1-3}$ The few longitudinal studies on the natural history ${ }^{4-7}$ have shown that the outcome based on symptoms, signs, and radiological changes varies greatly between subjects. These studies included only a few subjects, however, were retrospective in design, and most often based on selected patients from a hospital. Few prognostic factors were studied. Therefore they are of limited value for the study of prognostic factors to explain the variability in outcome. In a large longitudinal population based study, the National Health and Nutrition Examination Survey-I Epidemiologic Follow-up Study, the natural history of radiological osteoarthritis of the knee was studied with mortality, symptoms, and functional limitations as outcome. ${ }^{8}$ Changes in the radiological signs of osteoarthritis, however, were not investigated. Only pain and swelling at baseline were evaluated as prognostic factors for pain and functional ability as outcome, but others were not.

Several prognostic factors could possibly explain the variability in outcome of osteoarthritis of the knee. These could have an influence on its progression through several mechanisms. Mechanical influences, increased joint use-for example, during work or sporting activities and traumatic events such as a meniscectomy-have been suggested as prognostic factors for cartilage defects. ${ }^{9}$ Obesity is also believed to be a prognostic factor, possibly due to increased knee loading, as patients with osteoarthritis of the knee are advised to reduce their weight. ${ }^{10}$ In one study it was reported that obesity was a prognostic factor, ${ }^{11}$ but no relation was found in two other studies. 57 Another mechanism could be increased inflammation in the joint due, for example, to gout or chondrocalcinosis. Chondrocalcinosis occurs more often in severe osteoarthritis, ${ }^{12}{ }^{13}$ though this could not be confirmed in a population based study. ${ }^{14}$ There could also be a (genetic) predisposition to develop more severe osteoarthritis. Generalised osteoarthritis or Heberden's nodes may reflect a genetic predisposition to the development of osteoarthritis in several joints, ${ }^{15}$ sometimes due to an abnormality of type II collagen gene. ${ }^{16-18}$

There is a need to elucidate factors that can prevent progression of osteoarthritis of the knee and for which longitudinal studies are preferred. In a general population survey for the study of rheumatic diseases that took place between 1975 and 1978 data were collected to study the prognostic factors of osteoarthritis of the knee. These factors are related to cartilage loss as a measure of progression and as all subjects studied had osteoarthritis at baseline this study does not elucidate factors related to the occurrence of osteoarthritis of the knee.

\section{Subjects and methods}

POPULATION SURVEY IN 1975-8

From 1975 to 1978 a population survey was undertaken in the Dutch town of Zoetermeer. The aim of this survey was to study the prevalence and risk factors of several chronic diseases, especially rheumatic diseases, in subjects aged 20 years and older. Data were collected by a self administered questionnaire, physical examination, radiographs, and serum analyses. 
In the questionnaire information was obtained about gender, age, current physical activities (jogging or membership of a sporting club), and smoking.

Physical examination consisted of the assessment of Heberden's nodes and a diagnosis of generalised or localised osteoarthritis, and the measurement of body weight and length. Presence in at least one joint was considered to be positive for Heberden's nodes. A doctor diagnosed localised osteoarthritis or generalised osteoarthritis based on a physical examination without knowledge of the radiographic findings. A diagnosis of localised osteoarthritis was made when clinical osteoarthritis was considered to be present in one or two joint groups; a diagnosis of generalised osteoarthritis was made when three or more joint groups were affected. Body weight and length were measured with indoor clothing without shoes. The body mass index was calculated as weight divided by squared height $\left(\mathrm{kg} / \mathrm{m}^{2}\right)$.

Radiographs of the knees were taken in people aged 45 years and over as weightbearing anteroposterior radiographs. These were scored on a five point scale (0-4) in 1975-8 according to Kellgren et al. ${ }^{19}$ Two observers scored the first half of the radiographs. As one observer left the department during the survey, the second part of the radiographs were scored by a single observer (HAV). If the difference in score between the two observers was two or more or if one had scored 1 (doubtful) and the other had scored 2 (definite, but mild), the radiographs were reviewed by the two observers together during a consensus meeting. A score of grade 2 or more was considered to be positive for radiological osteoarthritis. If no consensus reading was necessary the highest score of the two observers was used in the analysis.

Serum analysis included the assessment of serum uric acid concentrations.

\section{FOLLOW UP IN 1988-9}

In 1988-9 a follow up took place of all the subjects born after 1909 who had a radiograph taken of the knees and also had a score of grade 2 or more in at least one knee joint.

The subjects with a score of grade 2 or more at baseline were asked to fill in a self administered questionnaire. This questionnaire included questions about trauma to the knee joint, sporting injuries to the knee joint, meniscectomy, and the presence of bow legs or knock knees in childhood. An occupational history was also included with detailed questions about the type of occupation, number of years of employment in these jobs, lifting heavy objects, knocking one's knee, and other questions about knee loadings (hours of walking, standing, squatting, kneeling, and crawling). These last three aspects were combined in one question. A score based on a scoring system developed by another institution was given for the physical demands of the jobs. ${ }^{20}$

The radiographs taken at baseline were reevaluated in 1989 independently by two observers according to the same procedures and criteria as in 1975-8. If the score on the radiograph was confirmed to be 2 or more then the subject was included in the analysis. For those who had bilateral osteoarthritis determined radiographically only one randomly assigned knee was used in the analysis. During the second reading in 1989 chondrocalcinosis was scored separately on a four point scale (0-3) for the medial and lateral joint spaces. The medial and lateral scores were added because of the small number of subjects, and the mean score of the two observers combined. A mean score of 0.5 or more was regarded as positive for chondrocalcinosis.

In 1988-9 the radiographs of the knee joint were taken in the same way as at baseline in 1975-8. The only outcome measure used in this study was cartilage loss, scored as the change in joint space width between the two radiographs and assessed independently by two observers without any knowledge of other data. The observers scored the change in joint space width between the radiograph taken at baseline and the radiograph taken at follow up with the two radiographs placed side by side on the screen. The score, on a nine point scale, ranged from -4 to +4 depending on whether there was a decrease or increase in joint space width. Change in joint space width was scored for the medial and lateral side separately. The mean of the scores of the two observers was calculated and used in the analysis except when the difference was 3 or more or if one had scored -2 and the other 0 or -1 and +1 . These radiographs were judged again during a consensus meeting of the two observers. With this procedure coding errors were corrected and discrepancies around the point of whether or not there was change were critically reviewed. When there was a difference in change between the two knee compartments, lateral and medial, the compartment with the largest decrease in joint space width or the smallest increase was used in the analysis. The reason for this choice was that cartilage loss in one compartment may result in widening of the other. A mean score of -1 or lower was considered to indicate cartilage loss and this cutoff point was assessed before any association was analysed. The outcome measure was dichotomised (though it was assessed as an ordinal variable on a nine point scale) to compare those subjects with to those subjects without cartilage loss and to be able to apply a logistic regression analysis to adjust for confounding variables.

\section{STATISTICAL ANALYSIS}

The (baseline) characteristics for the total group were calculated and cutoff points determined for several continuous prognostic factors. Age was categorised in five year age intervals. Cutoff points for body mass index were quartiles and cutoff points for body weight and uric acid concentrations were tertiles. The scores based on the answers to the questionnaire for occupation related factors or the score for physical activity were multiplied with the years of employment in that job, including the years between the first and second radiograph, and all these values were added for all the jobs a respondent had had to form one sum score. In the analysis cutoff points were based on these 
Table 1 Response, radiological diagnoses, and cartilage loss in subjects with radiological osteoarthritis (ROA) of the knee

\begin{tabular}{lc}
\hline & $\begin{array}{c}\text { No (\%) of } \\
\text { subjects }\end{array}$ \\
\hline ROA grade 2 or more at baseline & 422 \\
Died & $58(14)$ \\
Lost to follow up & $36(9)$ \\
Eligible for follow up & $328(78)$ \\
Response & $239(73)$ \\
Radiographs judged in 1989 & 233 \\
ROA grade 2 after re-evaluation & $142(100)$ \\
Bilateral osteoarthritis & $51(36)$ \\
Right knee & $95(67)$ \\
Left knee & $98(69)$ \\
Radiographs from 1975 to 1978 & \\
Grade 2 (1989 score) & $121(85)$ \\
Grade 3 or 4 (1989 score) & $21(15)$ \\
Radiographs from 1988 to 1989 & \\
Grade 0 or 1 & $15(11)$ \\
Grade 2 & $58(41)$ \\
Grade 3 or 4 & $69(49)$ \\
Cartilage loss & $48(34)$ \\
\hline
\end{tabular}

Table 2 Characteristics of subjects with radiological osteoarthritis of the knee

\begin{tabular}{ll}
\hline Mean (SD) duration of follow up (years) & $12 \cdot 2(0 \cdot 9)$ \\
Mean (SD) age at baseline (years) & $57 \cdot 2(6 \cdot 1)$ \\
Age range at baseline (years) & $46-68$ \\
Mean (SD) age at follow up (years) & $68 \cdot 8(6 \cdot 1)$ \\
Age range at follow up (years) & $58-79$ \\
Mean (SD) body mass index (kg/m $\left.{ }^{2}\right)(B)^{*}$ & $26 \cdot 4(3 \cdot 0)$ \\
Mean (SD) body weight (kg) (B) & $73 \cdot 9(10 \cdot 5)$ \\
Mean (SD) uric acid concentration (mg/l) & \\
(B) (n=141) & $51(14)$ \\
Gender (male/female) & $58 / 84(41 / 59)$ \\
No (\%) with meniscectomy (F)* & $13(9)$ \\
No (\%) with injury to the knee joint (F) & $27(19)$ \\
No (\%) with injury to the knee joint & $19(13)$ \\
during sport (F) & $25(18)$ \\
No (\%) with jogging or member of sporting & \\
club (B) & $10(7)$ \\
No (\%) with childhood bow legs or knock & $13(9)$ \\
knees (F) & $15(11)$ \\
No (\%) with chondrocalcinosis (B) & \\
No (\%) with Heberden's nodes (B) & $38(27)$ \\
No (\%) with diagnosis of generalised & \\
osteoarthritis (B) & $47(33)$ \\
No (\%) with diagnosis of localised & \\
osteoarthritis (B) & $53(37)$ \\
No (\%) smoking (B) & $44(31)$ \\
Never smoked & $45(32)$ \\
Smoked in past & \\
Current smoker &
\end{tabular}

${ }^{\mathrm{N}} \mathrm{B}=$ assessed at baseline; $\mathrm{F}=$ assessed at follow up. sum scores and tertiles were chosen as the cutoff point. When, however, more than one third had a score of 0 , the cutoff point was set at 0 and the other cutoff point divided the group with a score of more than $\mathbf{0}$ into two groups of equal size.

The percentage of subjects with cartilage loss was calculated for several prognostic factors. The odds ratios (ORs) and $95 \%$ confidence intervals were calculated as the measure of effect and precision respectively. A logistic regression model was used to adjust for possible confounders. For this model it is necessary to have a dichotomised variable $(0 / 1)$ as a dependent variable-in this study absence or presence of cartilage loss. Every variable was adjusted for age, gender, and body mass index.

\section{Results}

Table 1 gives the response and radiographic findings in 1975-8 and 1988-9. Thirty four per cent of subjects had cartilage loss in the affected joint over a 12 year period. Table 2 gives the characteristics of the subjects.

Tables 3 and 4 give the percentage of subjects with cartilage loss and the unadjusted ORs with $95 \%$ confidence intervals for several prognostic factors. Body mass index, body weight, uric acid concentration, chondrocalcinosis, Heberden's nodes, and a diagnosis of generalised osteoarthritis were all related to cartilage loss. Age, gender, meniscectomy, (sport) injury to the knee joint, bow legs or knock knees, jogging or member of a sporting club, diagnosis of localised osteoarthritis, and smoking did not show a relation with cartilage loss.

Tables 3 and 4 also show the results after adjusting for the potential confounders age, gender, and body mass index. Age, body mass index, weight, bow legs or knock knees, Heberden's nodes and generalised osteoarthritis were related to cartilage loss. Adding Heberden's nodes or generalised osteoarthritis to the model with gender, body mass index,

Table 3 Cumulative risks, unadjusted and adjusted odds ratios of categorised continuously distributed prognostic factors assessed at baseline for cartilage loss in 142 subjects with radiological osteoarthritis of the knee from the general population

\begin{tabular}{|c|c|c|c|}
\hline & $\begin{array}{l}\text { No (\%) with } \\
\text { progression/total }\end{array}$ & $\begin{array}{l}\text { Odds ratio } \\
\left(95 \%(I I)^{*}\right.\end{array}$ & $\begin{array}{l}\text { Adjusted odds } \\
\text { ratio }(95 \%(\mathrm{CI}) *\end{array}$ \\
\hline $\begin{array}{l}\text { Age (years) (B) } † \ddagger \\
45-49 \\
50-54 \\
55-59 \\
>60\end{array}$ & $\begin{aligned} 5 / 22 & (23) \\
10 / 36 & (28) \\
9 / 31 & (29) \\
24 / 53 & (45)\end{aligned}$ & $\begin{array}{l}1 \\
1.31(0.38 \text { to } 4.50) \\
1.39(0.39 \text { to } 4.92) \\
2.82(0.90 \text { to } 8.76)\end{array}$ & $\begin{array}{l}1 \\
2.21(0.57 \text { to } 8.66) \\
1.94(0.49 \text { to } 7.61) \\
3.84(1.10 \text { to } 13.4)\end{array}$ \\
\hline $\begin{array}{l}\text { Body mass index }\left(\mathrm{kg} / \mathrm{m}^{2}\right)(\mathrm{B}) \Phi \\
<24.35 \\
24.35-25.96 \\
25.97-27.73 \\
>27.73\end{array}$ & $\begin{aligned} & 5 / 35(14) \\
& 7 / 34(21) \\
& 14 / 36(39) \\
& 22 / 37(60)\end{aligned}$ & $\begin{array}{l}1 \\
1.56(0.44 \text { to } 5 \cdot 49) \\
3.82(1.20 \text { to } 12 \cdot 2) \\
8.80(2.78 \text { to } 27 \cdot 8)\end{array}$ & $\begin{array}{l}1.77(0.48 \text { to } 6 \cdot 50) \\
1 \cdot 28(1.54 \text { to } 18 \cdot 1) \\
11 \cdot 1(3 \cdot 28 \text { to } 37 \cdot 3)\end{array}$ \\
\hline $\begin{array}{l}\text { Weight }(\mathrm{kg})(\mathrm{B}) \uparrow \\
<69 \\
69-78 \\
>78\end{array}$ & $\begin{array}{r}7 / 45(16) \\
16 / 51(31) \\
25 / 46(54)\end{array}$ & $\begin{array}{llll}1 & & & \\
2.48 & (0.91 & 10 & 6.74) \\
6.46 & (2.39 & 10 & 17.5)\end{array}$ & $\begin{array}{l}1 \\
2.95(1.03 \text { to } 8.46) \\
7.94(2.62 \text { to } 24.0)\end{array}$ \\
\hline $\begin{array}{l}\text { Uric acid concentration }(\mathrm{mg} / \mathrm{l})(\mathrm{B}) \mathrm{I} \\
<43 \\
43-54 \\
>54\end{array}$ & $\begin{array}{l}10 / 45(22) \\
17 / 48(35) \\
21 / 48(44)\end{array}$ & 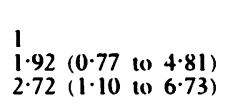 & $\begin{array}{l}1 \\
1.05(0.36 \text { to } 3.00) \\
1.36(0.46 \text { to } 4.02)\end{array}$ \\
\hline
\end{tabular}

*95\% confidence interval.

$+\mathrm{B}=$ assessed at baseline.

$¥$ Adjusted for gender and body mass index.

\$Adjusted for gender and age.

IAdjusted for age, gender, body mass index; $n=141$. 
Table 4 Cumulative incidence and unadjusted and adjusted odds ratios of categorised prognostic factors for cartilage loss in 142 subjects with radiological osteoarthritis of the knee from the general population

\begin{tabular}{|c|c|c|c|c|}
\hline \multirow[t]{3}{*}{ Parameter } & \multirow{2}{*}{\multicolumn{2}{|c|}{$\begin{array}{l}\text { Cumulative incidence (\%) } \\
\text { Prognostic factor }\end{array}$}} & \multirow[t]{3}{*}{ Odds ratio $(95 \% \mathrm{CI}) t$} & \multirow{3}{*}{$\begin{array}{l}\text { Adjusted odds ratio } \\
(95 \%(C I)\end{array}$} \\
\hline & & & & \\
\hline & Absent & Present & & \\
\hline $\begin{array}{l}\text { Gender }(\text { male }=0, \text { female }=1) \\
\text { Meniscectomy }(F) \\
\text { Injury to the knee joint }(F) \\
\text { Sport injury to knee joint }(F) \\
\text { Jogging or member of sporting club }(B) \\
\text { Bow legs or knock knees }(F) \\
\text { Chondrocalcinosis (B) } \\
\text { Heberden's nodes (B) } \\
\text { Diagnosis of generalised osteoarthritis (B) } \\
\text { Diagnosis of localised osteoarthritis (B) } \\
\text { Smoking (B) }\end{array}$ & $\begin{array}{l}40 \\
33 \\
30 \\
35 \\
36 \\
32 \\
31 \\
30 \\
25 \\
33\end{array}$ & $\begin{array}{l}30 \\
46 \\
48 \\
26 \\
24 \\
60 \\
62 \\
67 \\
58 \\
36\end{array}$ & $\begin{array}{l}0.65(0.32 \text { to } 1.30) \\
1.78(0.56 \text { to } 5.61) \\
2.12(0.90 \text { to } 4.98) \\
0.66(0.22 \text { to } 1.97) \\
0.56(0.21 \text { to } 1.52) \\
3.21(0.86 \text { to } 12.0) \\
3.56(1.10 \text { to } 11.6) \\
4.68(1.50 \text { to } 14.6) \\
4.13(1.89 \text { to } 9.02) \\
1.17(0.56 \text { to } 2.43)\end{array}$ & $\begin{array}{l}0.50(0.22 \text { to } 1.11) \\
2.28(0.57 \text { to } 9.03) \\
2.62(0.93 \text { to } 7.36) \\
0.62(0.17 \text { to } 2.19) \\
0.53(0.17 \text { to } 1.68) \\
5.13(1.14 \text { to } 23.1) \\
2.01(0.55 \text { to } 7.42) \\
5.97(1.54 \text { to } 23.1) \\
3.28(1.30 \text { to } 8.27) \\
1.17(0.51 \text { to } 2.72)\end{array}$ \\
\hline \multicolumn{5}{|l|}{ Smoking (B) } \\
\hline Smoked in past & - & 39 & $1.33(0.58$ to 3.08$)$ & $1.07(0.38$ to 3.04$)$ \\
\hline Current smoker (at baseline) & - & 31 & $0.96(0.41$ to $2 \cdot 25)$ & $0.96(0.34$ to 2.75$)$ \\
\hline
\end{tabular}

${ }^{*} \mathrm{~B}=$ assessed at baseline; $\mathrm{F}=$ assessed at follow up.

$+95 \%$ confidence interval.

tOdds ratio adjusted for age, gender, and body mass index.

SAdjusted for age and body mass index.

Table 5 Unadjusted and adjusted odds ratios of several occupation related prognostic factors for cartilage loss in 105 subjects with radiological osteoarthritis of the knee from the general population who had been or still are employed

\begin{tabular}{|c|c|c|}
\hline Prognostic factor & Odds ratio $(95 \%$ CI $) t$ & $\begin{array}{l}\text { Adjusted odds rutio } \neq \\
(95 \% \text { CI }) \text { t }\end{array}$ \\
\hline $\begin{array}{l}\text { Physical activity } \\
\text { Medium } \\
\text { High }\end{array}$ & $\begin{array}{l}1.28(0.48 \text { to } 3.38) \\
1.00(0.37 \text { to } 2.69)\end{array}$ & $\begin{array}{l}1.50(0.48 \text { to } 4.69) \\
0.43(0.11 \text { to } 1.76)\end{array}$ \\
\hline $\begin{array}{l}\text { Walking } \\
\text { Medium } \\
\text { High }\end{array}$ & $\begin{array}{l}1.85(0.67 \text { to } 5: 13) \\
1.98(0.72 \text { to } 5.44)\end{array}$ & $\begin{array}{l}2.09(0.61 \text { to } 7.20) \\
1.47(0.36 \text { to } 6.03)\end{array}$ \\
\hline $\begin{array}{l}\text { Standing } \\
\text { Medium } \\
\text { High }\end{array}$ & $\begin{array}{l}3.45(1.20 \text { to } 9.95) \\
2.57(0.87 \text { to } 7.61)\end{array}$ & $\begin{array}{l}3.80(1.03 \text { to } 13.96) \\
2.09(0.43 \text { to } 10.31)\end{array}$ \\
\hline $\begin{array}{l}\text { Squatting, kneeling, crawling } \\
\text { Medium } \\
\text { High }\end{array}$ & $\begin{array}{l}0.67(0.25 \text { to } 1.81) \\
0.42(0.15 \text { to } 1.22)\end{array}$ & $\begin{array}{l}1.18(0.36 \text { to } 3.89) \\
0.31(0.09 \text { to } 1.04)\end{array}$ \\
\hline $\begin{array}{l}\text { Knee knocking } \\
\text { Medium } \\
\text { High }\end{array}$ & $\begin{array}{l}0.51(0.19 \text { to } 1.35) \\
0.56(0.21 \text { to } 1.50)\end{array}$ & $\begin{array}{l}0.71(0.22 \text { to } 2.24) \\
0.36(0.11 \text { to } 1.15)\end{array}$ \\
\hline $\begin{array}{l}\text { Lifting heavy objects } \\
\text { Medium } \\
\text { High }\end{array}$ & $\begin{array}{l}0.92(0.35 \text { to } 2.46) \\
0.96(0.36 \text { to } 2.51)\end{array}$ & $\begin{array}{l}1.00(0.33 \text { to } 3.02) \\
0.65(0.19 \text { to } 2.28)\end{array}$ \\
\hline
\end{tabular}

* Lowest level as reference for every prognostic factor.

$+95 \%$ confidence interval.

†Adjusted for age, gender, and body mass index. research. ${ }^{19} 2122$ For the study of prognostic factors it is an improvement if false positives are excluded and we therefore included only those in whom the presence of radiologically detectable osteoarthritis was confirmed. Although this gives smaller numbers, the bias resulting from studying a group with a large number of subjects with doubtful or no osteoarthritis is reduced. The large number excluded (91 of 233) was partly due to the fact that half of the 233 films were read by a single observer (HAV) in $1975-8$. Of these radiographs only $55 \%$ were considered to have osteoarthritis when reevaluated in 1989 compared with $80 \%$ of the radiographs read by two observers in 1975-8. The one observer preferred to score with a high sensitivity but with a concomitant low specificity not to lose information. Lateral radiographs were not taken at baseline and could therefore not be used to study the progression of osteoarthritis. We have taken lateral radiographs at follow up in 217 subjects as part of a validation study of the American College of Rheumatology criteria for osteoarthritis of the knee (Schouten et al, unpublished data). ${ }^{23}$ Preliminary results indicate that the lateral radiograph did not contribute much to the diagnosis of osteoarthritis if the presence of osteophytes was not only assessed on the anteroposterior radiograph but also on the patella on the lateral radiograph (Schouten et al, unpublished observations). We think that our results are still valid but the generalisation is limited to the femorotibial joint. Moreover it is difficult to score cartilage loss of the patellofemoral joint on a lateral radiograph. Cartilage loss is regarded as the central pathological feature of osteoarthritis and was therefore used as the only outcome for disease progression in this study. Cartilage loss could be assessed by scoring the joint space difference between two radiographs taken more than 12 years apart. Joint space narrowing is considered to be the most important variable to assess the progression of knee osteoarthritis, ${ }^{11}$ has good inter-reader agreement, test retest correlation and construct validity, and scoring the joint space was found to be superior to measuring the joint space in detecting the 
correct time sequence of two consecutive radiographs. " In our study the interobserver agreement for joint space change was $86 \%$ ( $x$ $0 \cdot 70$ ). Intraobserver agreement was not assessed but is likely to be even higher. Cartilage thickness measured on anteroposterior radiographs correlated with actual cartilage thickness, ${ }^{24}$ but cartilage thickness on radiographs was found to correlate imperfectly with cartilage defects seen during arthroscopy. ${ }^{25}$ How these results can be applied to the detection of cartilage loss by judging change in joint space width remains a subject for further study. No other method is currently available for the study of progression of osteoarthritic abnormalities in epidemiological research. If non-differential misclassification can be assumed to be present, the observed relations would be stronger. In our study the radiographs were read as pairs (as in the study of Altman et al ${ }^{11}$ ) to detect even small changes. The readings of change in joint space width were performed without any knowledge of the other data except the presence of chondrocalcinosis on the first radiograph, thereby excluding the possibility of information bias.

In this study there was a relation between age and cartilage loss after adjusting for body mass index and gender but this relation became less strong and non-significant after adjusting for Heberden's nodes or generalised osteoarthritis. Although women had cartilage loss less often than men, women more often had severe progression when progression of cartilage loss had occurred (data not shown). Of the prognostic factors considered to have a mechanical influence, body mass index and body weight were found to be related to cartilage loss in subjects with knee osteoarthritis (table 3), confirming the observation of Altman et al that obesity is related to the progression of osteoarthritis. ${ }^{11}$ On the other hand injury to the knee joint and especially meniscectomy are unrelated to cartilage loss. As these factors were queried at follow up it cannot be excluded that these occurred as a result of progression. The year in which the injury or meniscectomy had taken place was also recorded. When the analysis was limited to those who had an injury before the first radiograph was taken (16 subjects) the OR was $2 \cdot 15(0.74$ to $6 \cdot 24)$ and for meniscectomy (11 subjects) $1 \cdot 12(0 \cdot 31$ to $4 \cdot 08)$. Repetitive impulse loading may lead to progressive cartilage loss. ${ }^{9}$ In certain occupations the stress on the joint may be increased and a kneebending requirement in employment is related to the occurrence of osteoarthritis of the knee. ${ }^{26} 27 \mathrm{~A}$ relation is found in this study between occupation related standing and cartilage loss. A lack of cyclic loading or continued pressure associated with standing possibly influences cartilage metabolism and results in cartilage loss $^{28} 29$ because cyclic loading increases production of cartilage matrix components. ${ }^{30}{ }^{31}$ It must be realised, however, that a selection of those subjects with a predisposition to develop progressive osteoarthritis for jobs with activities where knee loading is reduced might have occurred (healthy worker effect). This could also explain why no effect of other more traumatic occupation related factors was found. It is unlikely that the results are influenced by a change in employment as a result of progression as none of the subjects with knee pain had changed his or her job because of knee pain and only two subjects received social security payments because they were unable to work as a result of knee pain. Jogging or being a member of a sporting club (assessed at baseline) and sporting injury (asked at follow up) were unrelated to cartilage loss. This may also reflect a kind of 'healthy worker effect.' For sporting injuries it is also possible that the question was not accurate enough because it was not asked which knee had sustained the injury or when it had happened. On the other hand it may be that these activities were all within a physiological range as the cartilage will adapt to its requirements. Immobilisation leads to thinning of the cartilage and reduced proteoglycan production in animals ${ }^{32}$ and repetitive loading leads to increased production of cartilage matrix components. ${ }^{30} 31$ Valgus or varus deformity induces cartilage and bone changes similar to those found in osteoarthritis in animal experiments. ${ }^{33}$ The results support the idea that tibial osteotomy could be beneficial in osteoarthritis of the knee. ${ }^{34}$ As the question about bow legs or knock knees was asked in 1988-9, however, a recall bias cannot be completely excluded. The question about bow legs or knock knees referred to the early (childhood) presence of these knee abnormalities. Inflammation, possibly mediated by interleukin 1 , could influence cartilage loss. ${ }^{35}$ Inflammation may result from uric acid deposits (high serum concentrations of uric acid) or chondrocalcinosis. More severe osteoarthritis occurs in patients with chondrocalcinosis. ${ }^{12} 13$ In this study there was a relation between cartilage loss and chondrocalcinosis and uric acid but this was reduced after adjusting for age, gender, and body mass index. The relation between cartilage loss and Heberden's nodes and a clinical diagnosis of generalised osteoarthritis suggests some systemic influence on cartilage or a cartilage abnormality that is present in all the joints. In our study we have chosen to include all subjects with Heberden's nodes because of the small number of subjects affected. At baseline the score for Heberden's nodes was determined for the right and left hand but not separately for every distal interphalangeal joint. The OR for those 12 subjects with Heberden's nodes in both hands was $\mathbf{3 . 2 8}$ $(0.98$ to 10.99$)$. At follow up the nodes were assessed for every distal interphalangeal joint and the OR for those subjects with nodes in three or more joints was $2.86(0.61$ to 13.47$)$ and $1.07(0.30$ to 3.80$)$ for those with one or two nodes. We only used 129 subjects seen by one observer in this analysis to exclude a bias as some of those with knee pain who had more often cartilage loss were examined by other observers as part of a validation study of criteria for knee osteoarthritis (Schouten et al, unpublished data). It is known that Heberden's nodes and generalised osteoarthritis cluster in families ${ }^{15}$ and may result from type II collagen abnormalities. ${ }^{16-18}$ This finding also agrees with the observation of Doherty et al who showed 
that primary generalised osteoarthritis predisposes to the development of secondary osteoarthritis in the knee after meniscectomy, ${ }^{36}$ confirming that generalised osteoarthritis reflects some general influence on cartilage or a cartilage abnormality that is present in all the joints.

We thank Mrs C H L Valkenburg, Mrs A M ter Haar, Mrs H E de Bruin and Mr R E Rosier for their assistance and data management. Dr H C M Haanen is acknowledged for his contribution to the reading of the 1975-78 radiographs. This work was supported by a grant from SGO, an incentive work was supported by a grant from SGO, an incentive programme for medical research financed jointly by the Dutch
Ministry of Science and Education and the Ministry of Welfare, Public Health and Culture.

1 Dieppe $P$. Osteoarthritis: are we asking the wrong questions? Br 7 Rheumatol 1984; 23: 161-3.

2 Brandt K D, Mankin H J, Shulman L E, eds. Workshop on etiopathogenesis of osteoarthritis. $\mathcal{F}$ Rhermatol 1986; 13: $1126-60$.

3 Felson D T. Epidemiology of hip and knee osteoarthritis. Epidemiol Rev 1988; 10: 1-28.

4 Massardo L, Watt I, Cushnaghan J, Dieppe P. Osteoarthritis of the knee joint: an eight year prospective study. Ann Rheum Dis 1989; 48: 893-7.

5 Danielsson L, Hernborg J. Clinical and roentgenologic study of knee joints with osteophytes. Clin Orhop Res 1970; 69: 302-12.

6 Hernborg J S, Nilsson B E. The natural course of untreated osteoarthritis of the knee. Clin Orthop Res 1977; 123: $130-7$.

7 Miller R, Kettelkamp D B, Laubenthal K N, Karagiorgos A, Smidt G L. Quantitative correlations in degenerative arthritis of the knee. $\mathcal{F}$ Bone foint Surg [Am] 1973; 55: 956-62.

8 Lawrence R C, Everett D F, Hochberg M C. Arthritis. In: Cornoni-Huntley J C, Huntley R R, Feldman J J, eds. Health status and well-being of the elderly. New York: Oxford University Press, 1990: 136-51.

9 Radin E L. Factors influencing the progression of osteoarthrosis. In: Ewing J W, eds. Articular cartilage and knee joint function: basic science and arthroscopy. New York: Raven Press, 1990: 301-9.

10 Robinson $W \mathrm{D}$. Management of degenerative joint disease. In: Kelley W N, Harris E D, Ruddy S, Sledge C B, eds. Textbook of rheumatology. Philadelphia: Saunders, 1981: 1491-9.

11 Altman R D, Fries J F, Bloch D A, et al. Radiographic assessment of progression in osteoarthritis. Arthritis Rheum 1987; 30: 1214-25.

12 Resnick D, Niwayama G, Goergen T G, et al. Clinical, radiographic and pathologic abnormalities in calcium pyrophosphate dihydrate deposition disease (CPPD): pyrophosphate dinydrate deposition
pseudogout. Radiology 1977; 122: 1-15.

13 Gordon T P, MaCredie M, Smith M, Brooks P M, Ebert B. Articular chondrocalcinosis in a hospital population: an Australian experience. Aust N Z J Med 1984; 14: 655-9.

14 Felson D T, Anderson J J, Naimark A, Kannel W, Meenan R F. The prevalence of chondrocalcinosis in the elderly and its association with knee osteoarthritis: the Framingham and its association with knee osteoarthris.
study. I R Reumatol 1989; 16: 1241-5.

15 Kellgren J H, Lawrence J S, Bier F. Genetic factors in generalized osteoarthrosis. Ann Rheum Dis 1963; 22: $237-55$.

16 Patolie A, Väisänen P, Ott J, et al. Predisposition to familial osteoarthrosis linked to type II collagen gene. Lancet 1989; i: 924-7.

17 Knowlton R G, Katzenstein P L, Moskowitz R W, et al. Genetic linkage of a polymorphism in the type II procollagen gene (COL2A1) to primary osteoarthritis associated with mild chondrodysplasia. $N$ Engl 7 Med 1990; 322: $526-30$.

18 Ala-Kokko I, Baldwin C T, Moskowitz R W, Prockop D J. Single base mutation in the type II procollagen gene (COL2A1) as a cause of primary osteoarthritis associated with a mild chondrodysplasia. Proc Natl Acad Sci USA with a mild $6565-8$.

19 Kellgren J H, Jeffrey M R, Ball J, eds. The epidemiology of chronic rheumatism. Vol. II. Atlas of standard radiographs of arthritis. Oxford: Blackwell Scientific, 1963.

20 Dictionary of occupations. Department of Applied Sociology, Catholic University of Nijmegen, 1973.

21 Bennett P H, Wood P H N, eds. Population studies of the rheumatic diseases. International congress series no 148. Amsterdam: Excerpta Medica Foundation, 1968: 417-9.

22 Bennett P H, Burch T A. New York symposium on population studies in the rheumatic diseases: new diagnostic criteria. Bull Rheum Dis 1967; 17: 453-8.

23 Altman R, Asch E, Bloch D, et al. Development of criteria for the classification and reporting of osteoarthritis. Classification of osteoarthritis of the knee. Arthritis Rheum 1986; 29: 1039-49.

24 Dacre J E, Ng Y, Shanmuganthan K, James M, Pereira J, Tucker $A$. The relationship of radiographic joint space to actual cartilage thickness [abstract]. $B r \mathcal{~ R h e u m a t o l ~ 1 9 9 0 ; ~}$ 29 (suppl 2): 52.

25 Fife R S, Brandt K D, Braunstein E M, et al. Relationship between arthroscopic evidence of cartilage damage and radiographic evidence of joint space narrowing in early osteoarthritis of the knee. Arhritis Rheum 1991; 34: 377-81.

26 Anderson J J, Felson D T. Factors associated with osteoarthritis of the knee in the first National Health and Examination Survey (HANES I): evidence for an association with overweight, race, and physical demands of work. Am 7 Epidemiol 1988; 128: 179-89.

27 Felson D T, Hannan M T, Anderson J J, Naimark A. Occupational physical demands, knee bending and X-ray knee osteoarthritis: the Framingham study [abstract]. Arthritis Rheum 1990; 33 (suppl): S10.

28 O'Hara B P, Urban J P G, Marouds A. Influence of cyclic loading on the nutrition of articular cartilage. Ann Rheum Dis 1990; 49: 536-9.

29 James M J, Cleland L G, Rofe A M, Leslie A L. Intraarticular pressure and the relationship between synovial perfusion and metabolic demand. I Rheumatol 1990; 17: $521-7$.

30 Treadwell B V, Mankin H J. The synthetic processes of articular cartilage. Clin Orthop 1986; 213: 50-61.

31 van Kampen G P J, Veldhuiizen J P, Kuijer $R$, van de Stadt R J, Schipper C A. Cartilage response to mechanical force in high-density chondrocyte cultures. Arthritis Rheum 1985; in high-density $419-24$.

32 Palmoski M, Perricone E, Brandt K D. Development and reversal of a proteoglycan aggregation defect in normal canine knee cartilage after immobilization. Arthritis Rheum 1979; 22: 508-17.

33 Wu D D, Burr D B, Boyd R D, Radin E L. Bone and cartilage changes following experimental varus or valgus tibial angulation. $\mathcal{I}$ Orthop Res 1990; 8: 572-85.

34 Kettelkamp D B, Colyer R A. Osteoarthritis of the knee. In Moskowitz R W, Howell D S, Goldberg V M, Mankin H J, eds. Osteoarthritis. Diagnosis and management. Philadelphia: Saunders, 1984: 403-21.

35 Pujol I P, Loyau G. Interleukin-1 and osteoarthritis. Life Sci 1987; 41: 1187-98.

36 Doherty M, Watt I, Dieppe P. Influence of primary generalised osteoarthritis on development of secondary osteoarthritis. Lancet 1983; ii: 8-11. 